\author{
Henryk OTWINOWSKI ${ }^{1}$ \\ Vladimir P. ZHUKOV ${ }^{2}$ \\ Evgenii V. BAROCHKIN ${ }^{3}$
}

\title{
MATEMATYCZNE MODELOWANIE PODGRZEWACZA REGENERACYJNEGO WODY
}

\begin{abstract}
W artykule przedstawiono macierzowy model wielostopniowego wymiennika ciepła. W modelu rozpatrzono zagadnienie wymiany ciepła pomiędzy parą nasyconą i wodą. Opracowany model wykorzystano do obliczeń regeneracyjnego podgrzewacza wody zasilającej kocioł w obiegu siłowni cieplnej. W rozpatrywanym przypadku czynnikiem grzejnym jest para wodna, która ulega kondensacji podczas przekazywania ciepła wodzie zasilającej kocioł. Na podstawie równań bilansu energii otrzymano układ równań różniczkowych, opisujących zmianę stopnia suchości gorącego czynnika oraz temperatury chłodnego czynnika w funkcji powierzchni wymiennika ciepła. Rozwiązanie tego układu równań umożliwia wyznaczenie temperatury wody zasilającej i stopnia suchości pary grzejnej w dowolnym punkcie rozpatrywanego wymiennika wielostopniowego. Warunkiem koniecznym rozwiązania układu równań jest określenie kierunku przepływu czynników gorącego i chłodnego oraz znajomość ich parametrów na wejściu do wymiennika. W artykule przedstawiono zasady określania kierunku przepływu obydwu czynników oraz metodykę tworzenia macierzy blokowej wielostopniowego wymiennika ciepła. Na podstawie obliczeń przeprowadzono analizę, która wykazała, że wyniki obliczeń umożliwiają ocenę stanu pracy podgrzewacza regeneracyjnego wody zasilającej kocioł. Przedstawiony macierzowy model wielostopniowego wymiennika ciepła może być wykorzystany do analizy efektywności pracy podgrzewaczy regeneracyjnych stosowanych w energetyce zawodowej i przemysłowej, ciepłownictwie oraz wymienników płaszczowo-rurowych stosowanych w przemyśle chemicznym, petrochemicznym, rafineryjnym, spożywczym $\mathrm{i}$ innych.
\end{abstract}

Słowa kluczowe: wymiennik wielostopniowy, model macierzowy, przemiana fazowa, siłownia cieplna, woda zasilająca kocioł

\footnotetext{
${ }^{1}$ Autor do korespondencji: Henryk Otwinowski, Politechnika Częstochowska, al. Armii Krajowej 21, 42-201 Częstochowa, tel.: 343250 579, e-mail: otwinowski@imc.pcz.czest.pl.

2 Vladimir P. Zhukov, Ivanovo State Power Engineering University, Rabfakovskaya 34, 153003 Ivanovo, Russia.

${ }^{3}$ Evgenii V. Barochkin, Ivanovo State Power Engineering University, Rabfakovskaya 34, 153003 Ivanovo, Russia.
} 


\section{Wstęp}

W pracach $[1,2]$ przedstawiono modelowanie wymiany ciepła w urządzeniach wielostopniowych, w których nie występuje zmiana stanu skupienia czynników roboczych. W przemysłowych wymiennikach ciepła zdarza się często, że podczas wymiany ciepła stan skupienia jednego czynnika, a niekiedy obydwu, ulega zmianie. W niniejszej pracy przedstawiono model wielostopniowego wymiennika ciepła $\mathrm{z}$ uwzględnieniem przejścia fazowego czynnika roboczego. W szczególności rozpatrzono przemianę fazową gaz-ciecz dla pary wodnej i wody w powierzchniowym wymienniku ciepła.

\section{Model wielostopniowego wymiennika ciepła}

Przeponowy wymiennik ciepła (albo jego stopień) można przedstawić jako czterobiegunowy element o dwóch wchodzących i dwóch wychodzących strumieniach (rys.1) [1,2]. Parametry tych strumieni będą występować w równaniach, w których uwzględniono przejście fazowe. W modelu matematycznym wymiennika ciepła przyjęto następujące założenia:

- wymiana ciepła zachodzi pomiędzy wodą a parą nasyconą o temperaturze $\mathrm{T}_{\mathrm{n} 1}=\mathrm{idem}$,

- proces kondensacji pary będzie opisany za pomocą stopnia suchości pary $x$, - jako zmienną niezależną przyjmuje się powierzchnię czynną $F$ wymiennika, - nie uwzględnia się strat ciepła do otoczenia.

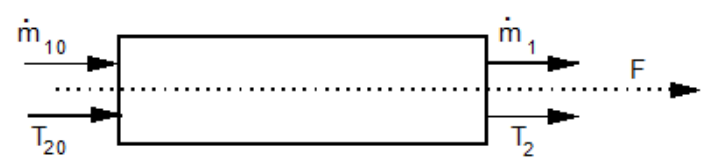

Rys. 1. Schemat pojedynczego stopnia wymiennika ciepła

Fig. 1. Schematic of a heat exchanger single stage

$\mathrm{Na}$ rysunku 2 przedstawiono schemat obliczeniowy strumieni ciepła przechodzących przez elementarną powierzchnię $d F$ współprądowego wymiennika ciepła. Na podstawie równań bilansu energii otrzymuje się układ równań różniczkowych opisujących zmianę stopnia suchości $x_{1}$ gorącego czynnika oraz temperatury $\mathrm{T}_{2}$ chłodnego czynnika wzdłuż powierzchni wymiennika:

$$
\left\{\begin{array}{l}
\frac{d x_{1}}{d F}=-a_{1}\left(T_{n 1}-T_{2}\right) \\
\frac{d T_{2}}{d F}=-a_{2}\left(T_{n 1}-T_{2}\right)
\end{array}\right.
$$




$$
a_{1}=\frac{k}{r_{1} \dot{m}_{1}}, \quad a_{2}=\frac{k}{c_{2} \dot{m}_{2}}
$$

gdzie: $k$ - współczynnik przenikania ciepła, $\mathrm{W} / \mathrm{m}^{2} \mathrm{~K}$;

$\dot{m}$ - strumień masy czynnika, $\mathrm{kg} / \mathrm{s}$;

$r$ - entalpia właściwa parowania wody, $\mathrm{J} / \mathrm{kgK}$;

$c$ - pojemność cieplna właściwa czynnika, $\mathrm{J} / \mathrm{kgK}$;

indeks 1 odnosi się do czynnika gorącego, a indeks 2 dotyczy czynnika chłodnego.

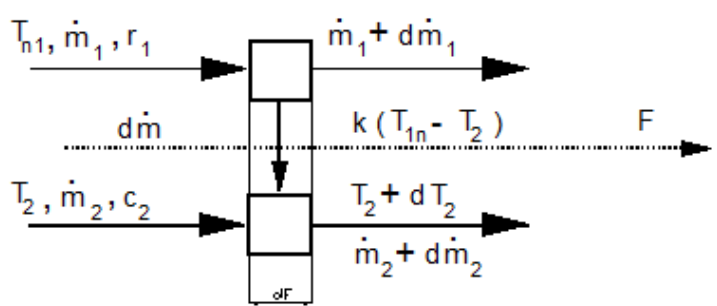

Rys. 2. Schemat przepływu czynników przez elementarną powierzchnię wymiany ciepła

Fig. 2. Schematic of the agents flow through an elementary heat exchange surface

Rozwiązanie układu równań (1) dla warunków początkowych:

$$
\left.x_{1}\right|_{F=0}=x_{10},\left.\quad T_{2}\right|_{F=0}=T_{20}
$$

można przedstawić w postaci macierzowej

$$
\left(\begin{array}{cccc}
1 & \frac{a_{1}}{a_{2}}\left(1-e^{-a_{2} F}\right) & -1 & 0 \\
0 & -e^{-a_{2} F} & 0 & 1
\end{array}\right)\left(\begin{array}{c}
x_{10} \\
T_{20} \\
x_{1} \\
T_{2}
\end{array}\right)=\left(\begin{array}{l}
\frac{a_{1}}{a_{2}}\left(1-e^{-a_{2} F}\right) T_{n 1} \\
\left(1-e^{-a_{2} F}\right) T_{n 1}
\end{array}\right)
$$

Jeżeli dane są dwa $\mathrm{z}$ czterech parametrów $\left(x_{10}, T_{20}, x_{1}, T_{1}\right)$, to na podstawie układu równań (2) można obliczyć dwa pozostałe parametry. W celu uogólnienia modelu rozszerzono układ (2) o równania zawierające dwa znane parametry na wejściu do wymiennika wielostopniowego (lub układu wymienników). Przykładowo dla znanych następujących parametrów: stopnia suchości gorącego czynnika oraz temperatury chłodnego czynnika na wejściu do wymiennika rozszerzony układ równań przyjmie następującą postać: 


$$
\left(\begin{array}{cccc}
1 & \frac{a_{1}}{a_{2}}\left(1-e^{-a_{2} F}\right) & -1 & 0 \\
0 & -e^{-a_{2} F} & 0 & 1 \\
1 & 0 & 0 & 0 \\
0 & 1 & 0 & 0
\end{array}\right)\left(\begin{array}{c}
x_{10} \\
T_{20} \\
x_{1} \\
T_{2}
\end{array}\right)=\left(\begin{array}{c}
\frac{a_{1}}{a_{2}}\left(1-e^{-a_{2} F}\right) T_{n 1} \\
\left.1-e^{-a_{2} F}\right) T_{n 1} \\
\tilde{x}_{10} \\
\tilde{T}_{20}
\end{array}\right)
$$

gdzie: $\tilde{x}_{10}, \widetilde{T}_{20}$ - wartości znanych parametrów na wejściu do układu wymienników, a położenie jedynki w odpowiednim wierszu macierzy współczynników wskazuje na miejsce, w którym występuje dany parametr.

Analizę układu, który składa się z $n$ wymienników ciepła połączonych w dowolny sposób przeprowadzono przyjmując następujące założenia:

- każdy wymiennik stanowi czterobiegunowy element o dwóch strumieniach czynników wchodzących i dwóch strumieniach czynników wychodzących,

- wartości parametrów na wyjściu z wymiennika i wejściu do kolejnego wymiennika są równe.

Strumienie czynników przepływających pomiędzy wymiennikami w rozpatrywanym układzie nazwano strumieniami wewnętrznymi, a strumienie czynników wchodzących lub wychodzących z układu nazwano strumieniami zewnętrznymi. Dla każdego wymiennika stanowiącego element układu można zapisać układ 4 równań analogicznych do układu równań (3). Układ równań dla $n$ wymienników ciepła zawiera $4 n$ równań - rozwiązanie tego układu umożliwia wyznaczenie temperatury chłodnego czynnika i stopnia suchości gorącego czynnika w dowolnym punkcie układu wymienników. Powyższa analiza jest słuszna również dla wymiennika wielostopniowego.

W celu określenia kierunków przepływu: czynnika gorącego, chłodnego oraz wspólnego dla obydwu czynników wprowadzono następujące macierze:

- dla czynnika gorącego

$$
\mathbf{G}=\left(\begin{array}{cccc}
0 & 0 & 0 & 0 \\
0 & 0 & 0 & 0 \\
-1 & 0 & 0 & 0 \\
0 & 0 & 0 & 0
\end{array}\right)
$$

- dla czynnika chłodnego 
$\mathbf{C}=\left(\begin{array}{cccc}0 & 0 & 0 & 0 \\ 0 & 0 & 0 & 0 \\ 0 & 0 & 0 & 0 \\ 0 & -1 & 0 & 0\end{array}\right)$

- dla obydwu czynników

$$
\mathbf{G C}=\left(\begin{array}{cccc}
0 & 0 & 0 & 0 \\
0 & 0 & 0 & 0 \\
-1 & 0 & 0 & 0 \\
0 & -1 & 0 & 0
\end{array}\right)
$$

Macierz współczynników dla $i$-tego wymiennika przyjmuje następującą postać:

$$
\mathbf{B}_{i}=\left(\begin{array}{cccc}
1 & \frac{a_{1 i}}{a_{2 i}}\left(1-e^{-a_{2 i} F_{i}}\right) & -1 & 0 \\
0 & -e^{-a_{2 i} F_{i}} & 0 & 1 \\
0 & 0 & 1 & 0 \\
0 & 0 & 0 & 1
\end{array}\right)
$$

Cztery parametry czynników dla $i$-tego wymiennika tworzą macierz jednokolumnową o wymiarze $4 \times 1$

$$
\mathbf{P}_{i}=\left(\begin{array}{c}
x_{10 i} \\
T_{20 i} \\
x_{1 i} \\
T_{2 i}
\end{array}\right)
$$

a elementy macierzy wyrazów wolnych dla $i$-tego wymiennika tworzą następującą macierz o takim samym wymiarze

$$
\mathbf{P}_{0 i}=\left(\begin{array}{c}
\frac{a_{1 i}}{a_{2 i}}\left(1-e^{-a_{2 i} F_{i}}\right) T_{n 1} \\
\left(1-e^{-a_{2 i} F_{i}}\right) T_{n 1} \\
0 \\
0
\end{array}\right)
$$


W powyższej macierzy dla wymiennika, do którego wpływają lub wypływają czynniki zewnętrzne, zamiast zer występują wartości parametrów czynników zewnętrznych: temperatury albo stopnia suchości. Układ $4 n$ równań liniowych dla układu $n$ wymienników ciepła (lub $n$-stopniowego wymiennika) w postaci macierzowej można przedstawić w następujący sposób:

$$
\left(\begin{array}{ccccc}
\mathbf{A}_{11} & \mathbf{A}_{12} & \mathbf{A}_{13} & \ldots & \mathbf{A}_{1 n} \\
\mathbf{A}_{21} & \mathbf{A}_{22} & \mathbf{A}_{23} & \ldots & \mathbf{A}_{2 n} \\
\mathbf{A}_{31} & \mathbf{A}_{32} & \mathbf{A}_{33} & \ldots & \mathbf{A}_{3 n} \\
\ldots & \ldots & \ldots & \ldots & \ldots \\
\mathbf{A}_{n 1} & \mathbf{A}_{n 2} & \mathbf{A}_{n 3} & \ldots & \mathbf{A}_{n n}
\end{array}\right)\left(\begin{array}{c}
\mathbf{P}_{1} \\
\mathbf{P}_{2} \\
\mathbf{P}_{3} \\
\ldots \\
\mathbf{P}_{n}
\end{array}\right)=\left(\begin{array}{c}
\mathbf{P}_{01} \\
\mathbf{P}_{02} \\
\mathbf{P}_{03} \\
\ldots \\
\mathbf{P}_{0 n}
\end{array}\right)
$$

gdzie: $\mathbf{A}$ - macierz blokowa układu wymienników, w której każdy blok $\mathbf{A}_{i j} \mathrm{o}$ wymiarze $4 \times 4$ odpowiada jednej z macierzy określonej równaniami (4)-(7). W celu obliczenia dowolnego układu składającego się z $n$ wymienników wystarczy utworzyć macierz blokową A o wymiarze $n \times n$ bloków (lub $4 n \times 4 n$ elementów) według następujących zasad:

1. Każdy wymiennik układu ma przyporządkowany numer $i \in(1, n)$.

2. W macierzy blokowej $\mathbf{A}$ wymiennikowi numer $i$ odpowiada $i$-ty wiersz. W każdym wierszu występują co najwyżej trzy bloki niezerowe.

3. Na głównej przekątnej macierzy $\mathbf{A}$ umieszczone są macierze współczynników (7) czyli $\mathbf{A}_{i i}=\mathbf{B}_{i}$.

4. Jeżeli gorący czynnik podawany jest $\mathrm{z} i$-tego do $j$-tego wymiennika, to $\mathbf{A}_{i j}=\mathbf{G}$.

5. Jeżeli chłodny czynnik podawany jest z $i$-tego do $j$-tego wymiennika, to $\mathbf{A}_{i j}=\mathbf{C}$.

6. Jeżeli obydwa czynniki podawane są z $i$-tego do $j$-tego wymiennika, to $\mathbf{A}_{i j}=\mathbf{G C}$.

7. Wszystkie pozostałe bloki macierzy A są równe zerowym macierzom kwadratowym czwartego stopnia $\mathbf{A}_{i j}=\mathbf{0}$.

8. Jednokolumnowa macierz blokowa nieznanych parametrów $\mathbf{P}$ zawiera $n$ macierzy (8) (lub $4 n$ elementów), odpowiadających parametrom czynników wewnątrz układu (stopień suchości lub temperatura).

9. Jednokolumnowa macierz blokowa wyrazów wolnych $\mathbf{P}_{\mathbf{0}}$ zawiera $n$ bloków analogicznych do macierzy (9) (albo $4 n$ elementów). W tej macierzy wprowadza się także w miejsce zer znane wartości parametrów strumieni zewnętrznych. 
Rozwiązanie układu równań (10) umożliwia określenie parametrów czynników w dowolnym punkcie układu wymienników lub wymiennika wielostopniowego.

\section{Obliczenia podgrzewacza regeneracyjnego wody}

W niniejszej części artykułu rozpatrzono przykład obliczenia podgrzewacza regeneracyjnego niskoprężnego typu PN-400-26-2 (rys.3) [4] stosowanego do podgrzewu kondensatu z turbiny parowej typu K-300-240 o mocy 312 MW [3]. Zakłada się, że para podawana jest do podgrzewacza w stanie nasycenia o stopniu suchości równym 1 . Para wychodząca $\mathrm{z}$ turbiny rozdziela się na dwa równoległe strumienie, z których jeden kierowany jest do podgrzewu pierwszego i drugiego biegu wody, a drugi strumień pary podawany jest do podgrzewu trzeciego i czwartego biegu wody. Powstający ze skroplenia pary grzejnej kondensat zbiera się $\mathrm{w}$ dolnej części podgrzewacza i poprzez regulator poziomu opuszcza wymiennik. Podwyższenie poziomu kondensatu może prowadzić do przedostawania się kropel wody do turbiny. $\mathrm{Z}$ kolei obniżenie poziomu wody może doprowadzić do przepływu pary przez wymiennik wskutek niecałkowitego skroplenia. Do prawidłowej pracy wymiennika wymagane jest całkowite skroplenie pary grzejnej.

Woda z przestrzeni wlotowej przez płaski pęczek rur przepływa do pierwszego pęczka rur w kształcie litery U (pierwszy i drugi bieg). Podgrzana woda przez komorę wylotową i drugi pęczek U-rurek opuszcza podgrzewacz (trzeci i czwarty bieg). Macierz blokowa A, utworzona dla tego wymiennika według podanych zasad, przyjmuje następującą postać:

$$
\mathbf{A}=\left(\begin{array}{cccccccccccccc}
\mathbf{B}_{1} & \mathbf{C} & \mathbf{0} & \mathbf{0} & \mathbf{0} & \mathbf{0} & \mathbf{G} & \mathbf{0} & \mathbf{0} & \mathbf{0} & \mathbf{0} & \mathbf{0} & \mathbf{0} & \mathbf{0} \\
\mathbf{0} & \mathbf{B}_{2} & \mathbf{G C} & \mathbf{0} & \mathbf{0} & \mathbf{0} & \mathbf{0} & \mathbf{0} & \mathbf{0} & \mathbf{0} & \mathbf{0} & \mathbf{0} & \mathbf{0} & \mathbf{0} \\
\mathbf{0} & \mathbf{0} & \mathbf{B}_{3} & \mathbf{C} & \mathbf{G} & \mathbf{0} & \mathbf{0} & \mathbf{0} & \mathbf{0} & \mathbf{0} & \mathbf{0} & \mathbf{0} & \mathbf{0} & \mathbf{0} \\
\mathbf{0} & \mathbf{0} & \mathbf{0} & \mathbf{B}_{4} & \mathbf{C} & \mathbf{0} & \mathbf{0} & \mathbf{0} & \mathbf{0} & \mathbf{0} & \mathbf{0} & \mathbf{0} & \mathbf{0} & \mathbf{0} \\
\mathbf{0} & \mathbf{0} & \mathbf{0} & \mathbf{G} & \mathbf{B}_{5} & \mathbf{C} & \mathbf{0} & \mathbf{0} & \mathbf{0} & \mathbf{0} & \mathbf{0} & \mathbf{0} & \mathbf{0} & \mathbf{0} \\
\mathbf{0} & \mathbf{G} & \mathbf{0} & \mathbf{0} & \mathbf{0} & \mathbf{B}_{6} & \mathbf{C} & \mathbf{0} & \mathbf{0} & \mathbf{0} & \mathbf{0} & \mathbf{0} & \mathbf{0} & \mathbf{0} \\
\mathbf{0} & \mathbf{0} & \mathbf{0} & \mathbf{0} & \mathbf{0} & \mathbf{G} & \mathbf{B}_{7} & \mathbf{C} & \mathbf{0} & \mathbf{0} & \mathbf{0} & \mathbf{0} & \mathbf{0} & \mathbf{0} \\
\mathbf{0} & \mathbf{0} & \mathbf{0} & \mathbf{0} & \mathbf{0} & \mathbf{0} & \mathbf{0} & \mathbf{B}_{\mathbf{8}} & \mathbf{G C} & \mathbf{0} & \mathbf{0} & \mathbf{0} & \mathbf{0} & \mathbf{0} \\
\mathbf{0} & \mathbf{0} & \mathbf{0} & \mathbf{0} & \mathbf{0} & \mathbf{0} & \mathbf{0} & \mathbf{0} & \mathbf{B}_{9} & \mathbf{C} & \mathbf{0} & \mathbf{0} & \mathbf{G} & \mathbf{0} \\
\mathbf{0} & \mathbf{0} & \mathbf{0} & \mathbf{0} & \mathbf{0} & \mathbf{0} & \mathbf{0} & \mathbf{0} & \mathbf{0} & \mathbf{B}_{10} & \mathbf{G C} & \mathbf{0} & \mathbf{0} & \mathbf{0} \\
\mathbf{0} & \mathbf{0} & \mathbf{0} & \mathbf{0} & \mathbf{0} & \mathbf{0} & \mathbf{0} & \mathbf{0} & \mathbf{0} & \mathbf{0} & \mathbf{B}_{11} & \mathbf{C} & \mathbf{0} & \mathbf{0} \\
\mathbf{0} & \mathbf{0} & \mathbf{0} & \mathbf{0} & \mathbf{0} & \mathbf{0} & \mathbf{0} & \mathbf{0} & \mathbf{0} & \mathbf{G} & \mathbf{0} & \mathbf{B}_{12} & \mathbf{C} & \mathbf{0} \\
\mathbf{0} & \mathbf{0} & \mathbf{0} & \mathbf{0} & \mathbf{0} & \mathbf{0} & \mathbf{0} & \mathbf{0} & \mathbf{0} & \mathbf{0} & \mathbf{0} & \mathbf{G} & \mathbf{B}_{13} & \mathbf{C} \\
\mathbf{0} & \mathbf{0} & \mathbf{0} & \mathbf{0} & \mathbf{0} & \mathbf{0} & \mathbf{0} & \mathbf{G} & \mathbf{0} & \mathbf{0} & \mathbf{0} & \mathbf{0} & \mathbf{0} & \mathbf{B}_{14}
\end{array}\right)
$$

Podczas tworzenia algorytmu obliczeniowego powierzchnię wymiennika podzielono na 14 stopni - elementów czterobiegunowych (rys. 3). Numeracja stopni jest zgodna z kierunkiem przepływu wody. Rurki wymiennika podzielono wzdłuż wysokości na cztery części: trzy biegi pary i odcinek powrotny. 
Stopnie o numerach 1-7 odpowiadają pierwszemu i drugiemu biegowi wody, a stopnie 8-14 - trzeciemu i czwartemu biegowi wody. Kierunki przepływu czynników i schemat obliczeniowy przedstawiono na rysunku 3. Rozwiązanie układu równań (10) pozwala wyznaczyć stopień suchości gorącego czynnika i temperaturę chłodnego czynnika.
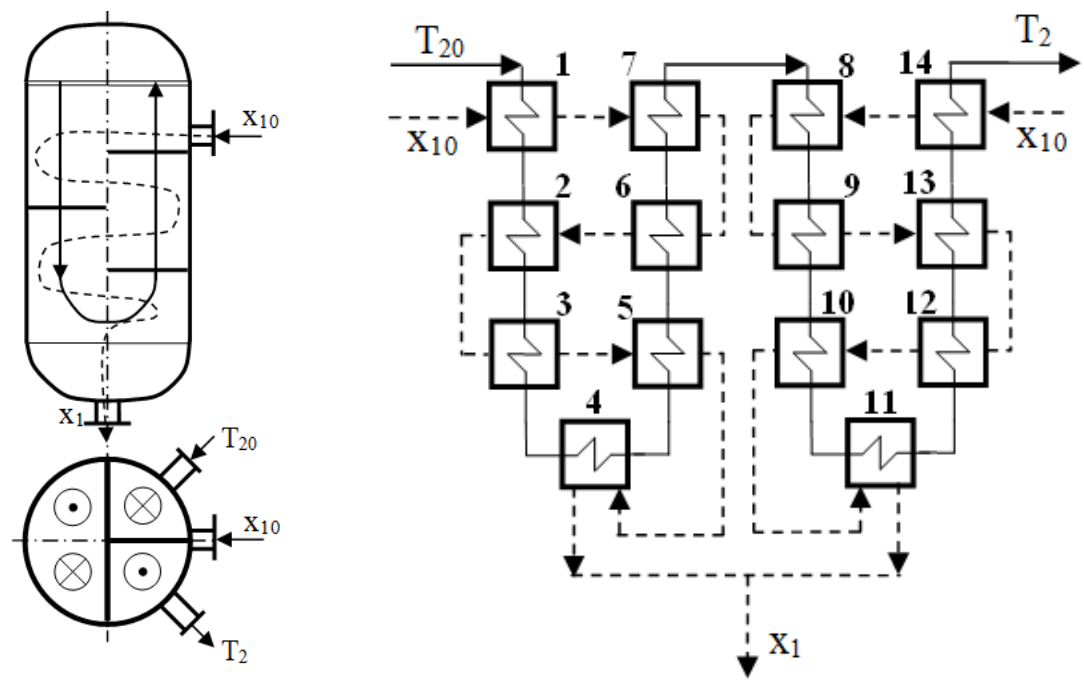

Rys. 3. Schemat obliczeniowy podgrzewacza regeneracyjnego wody

Fig. 3. Schematic of the regenerative feedwater heater calculation

Wyniki obliczeń przedstawiono na rysunkach 4 i 5 . Na rysunku 4 przedstawiono zależność stopnia suchości gorącego czynnika od numeru stopnia wymiennika dla różnych wartości strumienia masy pary grzejnej. Z rysunku wynika, że mały strumień masy (krzywa 3) prowadzi do całkowitego skroplenia pary już w środkowej części powierzchni wymiany ciepła, natomiast podwyższony strumień masy pary - do wypływu nieskroplonej pary z wymiennika (krzywa 1). Nominalne warunki eksploatacji odpowiadają kondensacji prawie całej pary grzejnej (krzywa 2). Na rysunku 5 przedstawiono zależność strumienia masy wody od strumienia masy pary przy całkowitym skropleniu pary grzejnej na wyjściu z wymiennika. 


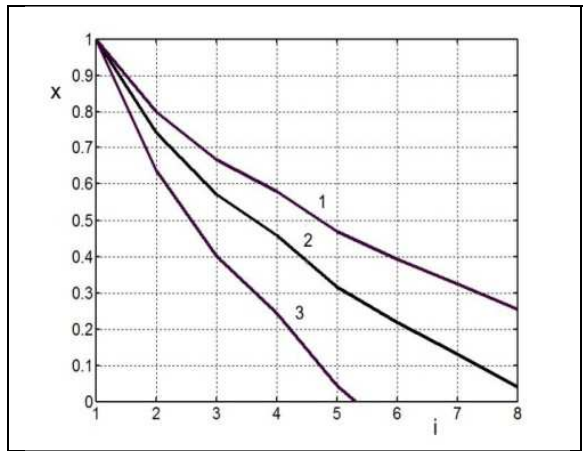

Rys. 4. Zależność stopnia suchości pary od numeru stopnia wymiennika dla różnych wartości strumienia masy pary grzejnej: $1-5$ $\mathrm{kg} / \mathrm{s}, 2-7 \mathrm{~kg} / \mathrm{s}, 3-9 \mathrm{~kg} / \mathrm{s}$

Fig. 4. Dependence of the steam dryness fraction on the stage number of exchanger for different values of the heating steam mass flowflux: $1-5 \mathrm{~kg} / \mathrm{s}, 2-7 \mathrm{~kg} / \mathrm{s}, 3-9 \mathrm{~kg} / \mathrm{s}$

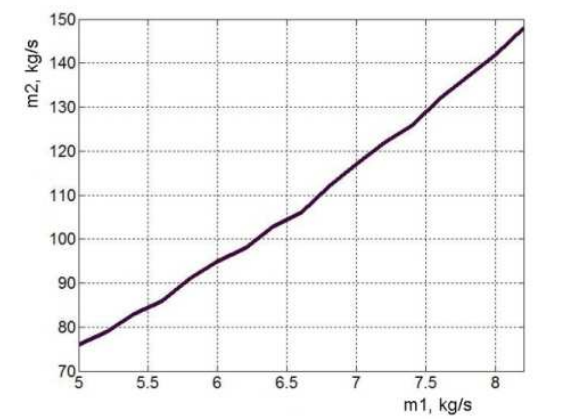

Rys. 5. Zależność strumienia masy wody od strumienia masy pary

Fig. 5. Dependence of the water mass flux on the steam mass flux

\section{Wnioski}

Porównanie teoretycznych i eksperymentalnych wyników dla podgrzewaczy przemysłowych umożliwia diagnozowanie stanu pracy wymiennika. W szczególności dobierając wartości współczynnika przenikania ciepła dla przypadków zbieżności wyników obliczeń i danych eksperymentalnych oraz porównując te wartości z danymi nominalnymi można diagnozować stan powierzchni ogrzewalnych wymiennika i wielkość zasysania gazów przez nieszczelności. Opracowana metoda umożliwia także przeprowadzenie analizy podawania do wymiennika dodatkowych strumieni czynników albo zmiany powierzchni wymiany ciepła. W związku z tym przedstawiony model może być wykorzystany do oceny efektywności pracy podgrzewaczy regeneracyjnych w energetyce, ciepłownictwie, przemyśle chemicznym, spożywczym i innych.

\section{Literatura}

[1] Barochkin E.V., Zhukov V.P., Mizonov V.E., Otwinowski H.: Recyrkulacja nośników ciepła w układach wymienników o złożonej konfiguracji, Izv. VUZ „Khimiya i khimicheskaya technologiya", vol. 48, nr 1, 2005, s. 124-128.

[2] Barochkin E.V., Zhukov V.P., Otwinowski H., Urbaniak D.: Modelowanie wielostopniowych wymienników ciepła, ZN Wydziału Inżynierii Procesowej, Materiałowej i Fizyki Stosowanej Politechniki Częstochowskiej, seria: Metalurgia, nr 48, 2005, s. 112-116. 
[3] Kostyuk A.G., Frolov V.V.: Turbiny elektrowni cieplnych i jądrowych, Izd. MEI, Moskwa 2001.

[4] Nazmeev Yu.G., Lavygin V.M.: Wymienniki elektrowni cieplnych, Energoatomizdat, Moskwa 1998.

\section{MATHEMATICAL MODELING OF THE REGENERATIVE FEEDWATER HEATER}

\section{S u m m a r y}

In the paper matrix model of the multistage heat exchanger is presented. The problem of heat exchange between the saturated steam and water is considered in this model. The developed model was used for the calculation of the regenerative boiler feedwater heater in a cycle of the thermal power plant. In the presented case, the water vapor is a heating medium that condenses during the heat transfer in the boiler feedwater. On the basis of the energy balance equations, the system of differential equations describing the change of the steam dryness fraction of warm media and temperature of the cooler media as a function of the heat exchanger area is obtained. The solution of this system of equations allows the determination of the feedwater temperature and the heating steam dryness fraction in any point of considered multistage heat exchanger. In order to solve the system of equations it is necessary to define the flow direction of both hot and cold media as well as knowledge of the parameters to input exchanger is needed too. The article presents the rules for determining the direction of both media flowing and methodology of creating a block matrix of multistage heat exchanger. On the basis of calculations the analysis was done, which shows that computation results allow to assess the operating conditions of regenerative boiler feedwater heater. The presented matrix model of the multistage heat exchanger can be used to analyze the efficiency of regenerative feedwater heaters used in the power industry, heating plants and tubular heat exchangers used in the chemical, petrochemical, refining, food and others industries.

Keywords: multistage exchanger, matrix model, phase transition, power plant, boiler feedwater

DOI: $10.7862 / \mathrm{rm} .2014 .27$

Otrzymano/received: 25.05.2014

Zaakceptowano/accepted: 28.06 .2014 